\title{
Combate à Insegurança Alimentar na Amazônia: a participação do PNUD
}

\author{
Lourrene de Cássia Alexandre Maffra ${ }^{1}$
}

\section{RESUMO}

Este paper objetiva apresentar alguns aspectos do programa conjunto entre o governo brasileiro e o Programa das Nações Unidas para o Desenvolvimento (PNUD) de enfrentamento à insegurança alimentar de povos nativos da Amazônia, com foco em mulheres e crianças indígenas, assim com seus resultados parciais.

Palavras-Chave: Insegurança Alimentar; PNUD; Amazônia

Em 2010, o governo brasileiro assinou um acordo com o sistema das Nações Unidas para implantar o Programa Conjunto de Segurança Alimentar e Nutricional de Mulheres e Crianças Indígenas (PCSAN) na região do Alto Rio Solimões (Amazonas) e Dourados (Mato Grosso do Sul). O principal articulador do programa foi o PNUD (Programa das Nações Unidas para o Desenvolvimento), mas contou com a assistência de outros órgãos das Nações Unidas, tais como FAO, OIT, OPAS/OMS e UNICEF e, pelo lado do governo brasileiro, o PCSAN contou com o auxílio da Fundação Nacional do Índio (FUNAI/Ministério da Justiça), da Secretaria Especial de Saúde Indígena (SESAI/Ministério da Saúde), do Ministério de Desenvolvimento Social e Combate à Fome (MDS) e da Agência Brasileira de Cooperação. A iniciativa do PSCAN foi financiada pelo Fundo para o Alcance dos Objetivos de Desenvolvimento do Milênio (da sigla em inglês MDG-F), criado a partir de doações do Governo da Espanha.

O PCSAN foi configurado para suprir uma necessidade que vem sendo observada na região amazônica com a expansão da produção de commodities, além do aumento da exportação de produtos básicos da alimentação indígena e da apropriação privada de terras antes destinadas ao uso coletivo das populações tradicionais. Nos

\footnotetext{
${ }^{1}$ Mestra pelo Programa de Integração da América Latina da USP e professora do curso de Relações Internacionais da Universidade Federal do Amapá (Unifap).
} 
últimos cinco anos, o preço de alimentos, como a mandioca e seus derivados, o açaí, a banana, disparou com o aumento das exportações para os EUA, Europa e China e, a população local, antes acostumada a ter esses alimentos todos os dias a mesa, encontrou-se desabastecida, tendo que incorporar alimentos industrializados a sua alimentação, tornando-a, assim, menos saudável.

A principal cultura que vem tomando espaço nas terras amazônicas é a soja, que avança desde a região centro-oeste. A soja, sendo um produto cultivado em geral para a exportação e tendo amplo espaço no mercado internacional (tanto em termo de preço, como de qualidade), tende a ser produzido a partir da incorporação de extensas faixas de terra. De acordo com Silva (2011, p. 7), nos estados de Tocantins e Rondônia "onde houve maior ritmo de avanço da monocultura de soja: a incorporação de áreas ao plantio variou 1.665,9\% no Tocantins e 1.572,8\% em Rondônia; a produção foi acrescida, nesses estados, de 2.382,3\% e 2.060\%, respectivamente" entre 1996 e 2006.

Já um dos principais produtos que fazem parte da alimentação amazônida, a mandioca (ou "macaxeira", como nos referimos na região Norte) é produzida por unidades familiares e para consumo local, e o excedente é comercializado para obtenção de outros produtos. 0 mesmo acontece com o açaí, produzido em ilhas perto de cidades. Entretanto, o açaí não tem perdido o seu espaço apenas por causa da expansão da soja, mas também porque vem sendo comercializado para o exterior e para outras regiões do Brasil em forma de polpa, o que tem deixado o mercado local sem o produto e com preço altíssimo, não acessível à população de baixa renda e que o utilizava como base da alimentação. Ambos são básicos na alimentação cotidiana do nortista e suprem boa parte das necessidades nutricionais (a mandioca, por exemplo, é o segundo alimento com maior teor de amido, perdendo apenas para o milho, e o açaí é rico em ferro).

Somados a esse cenário estão os problemas ambientais, tais como desmatamentos e poluições, assim como o aumento populacional na região Norte do Brasil, principalmente em áreas próximas a leitos de rios e florestas. A partir deste panorama, o governo brasileiro tem procurado apoio em diversos organismos internacionais para buscar soluções e compartilhar experiências.

Uma parceria que tem sido bastante frutífera é a do governo brasileiro com o PNUD e com outros órgãos das Nações Unidas. Como resultado, foi criado o Programa 
Conjunto de Segurança Alimentar e Nutricional de Mulheres e Crianças Indígenas (PCSAN) em 2010, que focava em uma atuação não apenas técnica, mas também de apoio institucional e de políticas públicas, o que proporciona expectativas de programas de médio a longo prazo. A atuação foi pensada em cinco eixos: fortalecimento institucional; empoderamento comunitário; produção de material culturalmente adaptado; disseminação de boas práticas e gestão, avaliação e monitoramento.

O primeiro passo da construção da atuação conjunta do PNUD-Governo do Brasil foi o estabelecimento de um diagnóstico da situação em que se encontravam os indígenas em termos de alimentação e, para isso, foi realizada a consulta prévia, conforme previsto na Convenção 169 da OIT (Organização Internacional do Trabalho), a qual prevê que povos indígenas e tribais terão que ser ouvidos quando uma política pública tiver conseqüências sobre sua rotina. A partir de então começou o processo de empoderamento comunitário e fortalecimento institucional, que também foi materializado em capacitações de 80 gestores indígenas sobre o Fundo Nacional de Desenvolvimento da Educação (FNDE) com objetivo de ajudarem na fiscalização das escolas quanto ao cardápio, presença de nutricionistas nas escolas e participação nos Conselhos de Alimentação Escolar. Esta ação também contou com o apoio técnico da FAO (Food and Agricultural Organization) e jurídico, bem como de fiscalização do Ministério Público.

Quanto às soluções mais rápidas e próximas dos indígenas, a equipe do PNUD preparou oficinas de técnicas para o melhor aproveitamento dos alimentos, tais como incluir legumes no preparo de alimentos básicos como arroz e feijão, utilização de cascas em preparos de bolos e geléias, além de dicas para armazenagem e conservação dos alimentos - já que muitos dos lugares atingidos têm pouco acesso à água potável e energia elétrica. Essas iniciativas contaram com o apoio da Organização Mundial Saúde da e da Rede Internacional em Defesa do Direito de Amamentar - Brasil e tentaram adaptar estratégias de alimentação à realidade local, o que é chamado pelo PNUD de "culturalmente referenciada".

Outras estratégias do PCSAN incluíram a implantação de hortas em 7 escolas indígenas, envolvendo 3.406 alunos na faixa etária 5 a 17 anos e 159 professores indígenas, os quais receberam treinamento de técnicos da FAO e os primeiros insumos 
para dar início às hortas, o estímulo à produção de artesanato a fim de garantir segurança alimentar na medida em que incentiva o desenvolvimento de práticas sustentáveis desde a cultura do alimento. Além disso, houve a produção editorial escrita e em áudio (em CD) do texto da Convenção 169 da OIT nos idiomas Guarani-Kaiowá e Terena, como parte da linha de ação de produção de material culturalmente adaptado.

Um bom indicativo dos benefícios do PCSAN às comunidades indígenas de Dourados e do Alto Solimões é o que podemos observar no depoimento (Boletim PCSAN, 2012, p. 31) do diretor da escola Pai Chikito em Panambizinho, Laucídio Flores:

\footnotetext{
Atualmente, estamos cultivando alface, cheiro verde, salsinha, couve, beterraba, berinjela, quiabo, mandioca, feijão. Já usamos os produtos na merenda escolar e, muitas vezes, os alunos, pais e professores levam para casa. Uma vez por semana, os alunos águam (sic) e cuidam das plantinhas. Cada semana é um professor que acompanha. A princípio, os alunos tiveram dúvidas. Horta não é da nossa cultura, mas vendo (sic) o sabor dos alimentos, como é bom para a saúde, a resistência acabou. Hoje, eles gostam bastante e comem mesmo. Algumas famílias já têm horta na casa e vejo mais união entre eles, mais amizade.
}

A administração do PCSAN pelo PNUD, com o apoio e participação de órgãos locais e centrais do governo brasileiro, tem logrado resultados bastante positivos para a coordenação de políticas públicas eficientes para os indígenas que vivem na região amazônica brasileira. Os principais resultados são a formação de futuros agentes disseminadores do PCSAN através do envolvimento de crianças e jovens nos processos de tomada de decisão e participação (um exemplo bem explícito são as hortas escolares), os métodos e procedimentos de instrução das famílias tornam o aprendizado e as práticas mais simples e autossustentáveis, proporcionando, assim, um ciclo virtuoso do projeto, além da harmonização dos interesses dos governos e da população indígena, que se torna menos suscetível a doenças causadas por alimentação inadequada.

\section{Referências Bibliográficas}

FAO. A mandioca tem um grande potencial de ser a cultura do século XXII. Disponível em <https://www.fao.org.br/mtgpcsXXI.asp> Acesso em 27 de maio de 2013.

PSCAN. ONU - BR. Boletim do PCSAN. Janeiro a Junho de 2012. Disponível em < http://www.pnud.org.br/Noticia.aspx?id=3660> Acesso entre 20 e 27 de maio de 2013. 
SILVA, José de Ribamar Sá. Produção de commodities, desmatamento e insegurança alimentar da Amazônia Brasileira. Revista Geográfica de América Central. Número Especial EGAL, 2011- Costa Rica, II Semestre 2011, pp. 1-15. 